\title{
EFEITO DE SISTEMAS DE MANEJO NA ESTABILIDADE DE AGREGADOS DE UM NITOSSOLO VERMELHO
}

\author{
NILDA B. LACERDA ${ }^{1}$, VÂNIA M. ZERO ${ }^{2}$, JULIANA BARILLI ${ }^{2}$, MARIA H. MORAES ${ }^{3}$ \\ SÍLVIO J. BICUDO ${ }^{4}$
}

RESUMO: Com o objetivo de avaliar o efeito do manejo do solo na estabilidade de agregados de um Nitossolo Vermelho distroférrico, localizado na Fazenda Experimental Lageado da FCA/UNESP, em Botucatu - SP, amostraram-se, em outubro de 2001, três sistemas de manejo de solo: (i) mata (MA), (ii) preparo convencional por 10 anos seguido de semeadura direta por 12 anos (PC/SD) e (iii) preparo convencional por 22 anos (PC), em quatro camadas: 0,0-0,10;0,10-0,20;0,20-0,30 e 0,30-0,40 m. O delineamento experimental empregado foi o inteiramente casualizado, com três repetições. As amostragens foram feitas após a cultura do milho (safra 2000-2001). As amostras foram submetidas às análises físicas e químicas, e as médias, comparadas pelo teste de Tukey. O diâmetro médio ponderado dos agregados (DMP), o índice de estabilidade dos agregados (IEA) e a percentagem de agregados em classes de diâmetro médio foram obtidos com os resultados do peneiramento obtidos pelo método por via úmida. O diâmetro médio ponderado e o índice de estabilidade dos agregados foram menores para o preparo convencional do solo. Os três sistemas de manejo apresentaram maior percentagem de agregados com diâmetro entre 7,93 e $2,00 \mathrm{~mm}$. A substituição do preparo convencional pela semeadura direta favoreceu a estabilidade dos agregados do solo. $\mathrm{O}$ diâmetro médio ponderado, o índice de estabilidade de agregados e a percentagem de agregados por classe de diâmetro médio evidenciaram diferenças entre os sistemas de manejo do solo.

PALAVRAS-CHAVE: diâmetro médio ponderado, índice de estabilidade de agregados, semeadura direta.

\section{EFFECT OF MANAGEMENT SYSTEMS ON THE AGGREGATE STABILITY OF AN ALFISOL}

\begin{abstract}
The purpose of this work was to evaluate the effect of soil management systems in the aggregate stability. The soil of the experimental site, classified as an Alfisol, according to the Brazilian System of Soil Classification, is located at the Lageado Experimental Farm, FCA/UNESP, in Botucatu - SP (Brazil). The effect of management practices was evaluated in the following treatments: native forest (MA), continuous conventional tillage for ten years followed by no-tillage for twelve years (PC/SD) and continuous conventional tillage for twenty two years (PC). The soil was sampled in four layers: $0.0-0.10 ; 0.10-0.20 ; 0.20-0.30$ and $0.30-0.40 \mathrm{~m}$. Soil samples were collected from each treatment in October 2001. The experimental design was completely randomized with three replicates. The wet soil aggregate stability was expressed as mean weight diameter (DMP), aggregate stability index (IEA) and percentage of aggregate size class. The DMP and the IEA were greater to the soil under native forest and conventional tillage/no-tillage. The three management systems presented larger aggregate percentage with diameter between 7.93 and $2.00 \mathrm{~mm}$. The change from conventional tillage to no-tillage improved the soil aggregate stability. The mean weight diameter, the aggregate stability index and the percentage of aggregate size class evidenced differences among the soil management systems.
\end{abstract}

KEYWORDS: mean weight diameter, aggregate stability index, and no-tillage.

\footnotetext{
${ }^{1}$ Doutora em Agronomia/Agricultura, Rua Cônego Bernardino Vieira, 101, Viraúna - PB, nildalacerda@ig.com.br

${ }^{2}$ Doutora em Agronomia/Agricultura, FCA/UNESP, Botucatu, SP.

${ }^{3}$ Professor Adjunto, Departamento de Recursos Naturais/Ciência do Solo, FCA/UNESP, Botucatu - SP.

${ }^{4}$ Professor Doutor, Departamento de Produção Vegetal/Agricultura, FCA/UNESP, Botucatu - SP.

Recebido pelo Conselho Editorial em: 17-1-2003

Aprovado pelo Conselho Editorial em: 22-9-2005
} 


\section{INTRODUÇÃO}

A degradação da estrutura causa ao solo perda das condições favoráveis ao desenvolvimento vegetal e o predispõe ao aumento de erosão hídrica. A rotação de culturas e o manejo do solo amenizam esses problemas e agem com o intuito de restaurar-lhe a estrutura. Diferentes práticas de manejo e sucessões de culturas induzem alterações nas propriedades do solo. A estabilidade dos agregados tem mostrado variação dependente do tipo de manejo do solo e das culturas (CAMPOS et al., 1995).

A formação e a estabilização dos agregados do solo ocorrem mediante a atuação de processos físicos, químicos e biológicos que, por sua vez, atuam por mecanismos próprios, nos quais são envolvidas substâncias que agem na agregação e na estabilização (SILVA \& MIELNICZUK, 1997a). A predominância do íon cálcio no complexo de troca, além de promover floculação adequada das argilas, contribui para intensa atividade biológica que favorece a formação de agregados. Por outro lado, com a predominância de sódio ou potássio no complexo de troca, ocorre dispersão excessiva dos colóides e, conseqüentemente, perda da estabilidade dos agregados (FASSBENDER, 1986).

CASTRO FILHO et al. (1998), avaliando parâmetros de agregação para os sistemas de manejo, preparo convencional e plantio direto, na camada de $0-0,1 \mathrm{~m}$, verificaram, para o plantio direto, aumentos relativos de $74 \%$ para o DMP, de $70 \%$ para o DMG e de 10,4\% para o IEA em relação ao preparo convencional. A maior agregação em semeadura direta foi relacionada ao maior acúmulo de matéria orgânica proporcionada por esse sistema em relação ao preparo convencional.

CARPENEDO \& MIELNICZUK (1990), avaliando a estabilidade e a qualidade dos agregados em água, de um Latossolo Roxo distrófico e um Latossolo Roxo álico, em condições naturais e sob diferentes manejos, constataram que o solo submetido ao preparo convencional apresentou menor agregação do que o sob mata nativa, e o plantio direto melhorou a agregação do solo e que as frações menores que $0,50 \mathrm{~mm}$ de diâmetro foram agregadas em frações maiores. SILVA \& MIELNICZUK (1997b) também encontraram menor agregação para o solo sob cultivo convencional com culturas anuais.

O sistema de semeadura direta tem-se mostrado promissor com relação à recuperação das propriedades físicas do solo. Após quatro anos de plantio direto, REINERT et al. (1984), trabalhando em Podzólico Vermelho-Amarelo distrófico, encontraram aumento de 2,2 vezes no DMG dos agregados em relação ao preparo convencional. Aumentos significativos também foram encontrados em Latossolo Vermelho-Escuro, por VIEIRA \& MUZILLI (1984) e CAMPOS et al. (1995), com valores de 1,42 (DMP) e 1,95 (DMG) vez maior, após quatro e sete anos de plantio direto, respectivamente, em relação ao preparo convencional.

BEUTLER et al. (2001) constataram que o sistema de semeadura direta foi o que apresentou a maior percentagem de agregados retidos na classe $>2,00 \mathrm{~mm}$. Esses resultados concordam com os de CAMPOS et al. (1995), que observaram que o sistema de plantio direto teve maior percentagem de agregados estáveis em água na classe de maior diâmetro $(8,00-4,76 \mathrm{~mm})$, em torno de $45 \%$. Já o sistema convencional mostrou concentração de agregados estáveis na classe de menor diâmetro $(1,00$ $0,21 \mathrm{~mm}$ ), em média $33 \%$ do total dos agregados.

MORAES et al. (2002), avaliando a estabilidade de agregados de um Nitossolo Vermelho para os sistemas de manejo em preparo convencional, por 20 anos, para a cultura do milho, preparo convencional, por 13 anos, seguido de semeadura direta por sete anos, com aveia-preta como cultura de inverno e milho como cultura de verão e mata nativa, verificaram para a condição de mata nativa e preparo convencional seguido pela semeadura direta maior diâmetro médio ponderado dos agregados.

O presente trabalho teve como objetivo avaliar o efeito de sistemas de manejo do solo na estabilidade dos agregados de um Nitossolo Vermelho distroférrico. 


\section{MATERIAL E MÉTODOS}

O trabalho foi realizado em Terra Roxa Estruturada, segundo CARVALHO et al. (1983), atualmente Nitossolo Vermelho Distroférrico textura argilosa, de acordo com os critérios do Sistema Brasileiro de Classificação de Solos (EMBRAPA, 1999), em área da Fazenda Experimental Lageado, da Faculdade de Ciências Agronômicas, Câmpus de Botucatu - UNESP, no município de Botucatu SP, na região Centro-Oeste do Estado, situada a $22^{\circ} 51^{\prime}$ de latitude sul, $48^{\circ} 26^{\prime}$ de longitude oeste, com altitude aproximada de $786 \mathrm{~m}$ acima do nível do mar. A área utilizada no experimento foi de aproximadamente 2,5 ha e as parcelas possuíam dimensões de 15 x $15 \mathrm{~m}$.

Os sistemas de manejo do solo estudados foram: mata (MA), preparo convencional por 10 anos seguido de semeadura direta por 12 anos (PCSD) e preparo convencional por 22 anos (PC). A caracterização granulométrica das áreas sob mata, preparo convencional e preparo convencional/ semeadura direta, realizadas de acordo com EMBRAPA (1997), constam da Tabela 1.

TABELA 1. Caracterização granulométrica das áreas sob mata, preparo convencional e preparo convencional/semeadura direta.

\begin{tabular}{cccccccccc}
\hline $\begin{array}{c}\text { Sistema } \\
\text { de } \\
\text { Manejo }\end{array}$ & $\begin{array}{c}\text { Camada } \\
(\mathrm{m})\end{array}$ & AMG & AG & AM & AF & AMF & AT & Silte & Argila \\
\cline { 3 - 9 } & $0-0,1$ & 10 & 15 & 20 & 100 & 80 & 225 & 130 & 645 \\
MA & $0,1-0,2$ & 11 & 15 & 17 & 94 & 79 & 216 & 126 & 658 \\
& $0,2-0,3$ & 5 & 15 & 10 & 90 & 60 & 180 & 120 & 700 \\
& $0,3-0,4$ & 10 & 16 & 17 & 105 & 55 & 203 & 130 & 667 \\
\hline \multirow{4}{*}{ PC } & $0-0,1$ & 3 & 6 & 25 & 84 & 41 & 159 & 170 & 671 \\
& $0,1-0,2$ & 2 & 6 & 23 & 83 & 41 & 155 & 165 & 680 \\
& $0,2-0,3$ & 1 & 3 & 22 & 79 & 41 & 146 & 164 & 690 \\
& $0,3-0,4$ & 1 & 4 & 23 & 80 & 40 & 148 & 162 & 690 \\
\hline \multirow{4}{*}{ PC/SD } & $0-0,1$ & 1 & 4 & 27 & 83 & 45 & 160 & 164 & 676 \\
& $0,1-0,2$ & 2 & 3 & 24 & 80 & 50 & 159 & 156 & 685 \\
& $0,2-0,3$ & 1 & 5 & 22 & 79 & 48 & 155 & 156 & 689 \\
\hline
\end{tabular}

$\mathrm{MA}=$ mata; $\mathrm{PC}=$ preparo convencional; $\mathrm{PC} / \mathrm{SD}$ preparo convencional/semeadura direta; $\mathrm{AMG}=$ areia muito grossa; $\mathrm{AG}=$ areia grossa; $\mathrm{AM}=$ areia média; $\mathrm{AF}=$ areia fina; $\mathrm{AMF}=$ areia muito fina; $\mathrm{AT}=$ areia total.

No preparo convencional do solo para a cultura do milho, utilizou-se de uma aração, com arado de disco entre 0 e $0,3 \mathrm{~m}$, e duas gradagens niveladoras. $\mathrm{O}$ sistema de semeadura direta caracterizou-se pela utilização do triticale (Triticale hexaploide Lart.) como cultura de inverno, seguida pela cultura do milho no verão. Empregou-se uma semeadora-adubadora de fluxo contínuo, com 15 linhas espaçadas de $200 \mathrm{~mm}$. Os tratamentos fitossanitários foram realizados sempre que necessário e de acordo com as recomendações.

A coleta de amostras de solo foi realizada após a colheita do milho (safra 2000-2001), nas camadas de $0-0,1 ; 0,1-0,2 ; 0,2-0,3$ e 0,3-0,4 m. Foram abertas três trincheiras por parcela, retirando-se uma amostra por camada de cada trincheira. As amostras foram retiradas com o auxílio de uma pá de corte e um enxadão, colocadas para secar ao ar por $56 \mathrm{~h}$, peneiradas em malha de 7,93 e de 2,00 mm, respectivamente, para as análises física e química do solo.

A percentagem de agregados, por classes de diâmetro médio, foi obtida submetendo-se as amostras de solo ao peneiramento a úmido, seguindo metodologia descrita por KIEHL (1979). Para isso, foram pesadas amostras de $25 \mathrm{~g}$, que ficaram retidas na peneira de $4 \mathrm{~mm}$, umedecidas com 
borrifador, colocadas no jogo de peneiras com malhas de 2,00;1,00;0,50;0,25 e 0,10 mm, e submetidas à agitação no aparelho de Yooder, durante 15 minutos. Após o tempo determinado, o material retido em cada peneira foi retirado, separadamente, com o auxílio de jato d'água, colocado em latas previamente pesadas e identificadas, e levado à estufa até peso constante.

Para obter o diâmetro médio ponderado e o índice de estabilidade dos agregados, foram utilizadas as seguintes equações, segundo CASTRO FILHO (1998):

$$
\mathrm{DMP}=\sum_{\mathrm{i}=1}^{\mathrm{n}}(\mathrm{xi} \text { wi) }
$$

em que,

DMP - diâmetro médio ponderado, mm;

xi - diâmetro médio das classes, mm, e

wi - proporção de cada classe em relação ao total.

$$
\mathrm{IEA}=\frac{\mathrm{MS}-\mathrm{wp} 0,25-\text { areia }}{\mathrm{MS}-\text { areia }} 100
$$

em que,

IEA - índice de estabilidade de agregados, \%;

MS - massa seca da amostra, g, e

wp0,25 - massa dos agregados da classe $<0,25 \mathrm{~mm}, \mathrm{~g}$.

O solo amostrado também foi submetido à análise química, determinando-se a matéria orgânica (M.O.), capacidade de troca de cátions (CTC), cálcio $(\mathrm{Ca})$, magnésio $(\mathrm{Mg})$ e potássio $(\mathrm{K})$, de acordo com a metodologia descrita por RAIJ \& QUAGGIO (1983).

O delineamento experimental utilizado foi o inteiramente casualizado, com três repetições.

Os resultados das propriedades estudadas foram submetidos à análise de variância, e a comparação entre médias foi feita pelo teste de Tukey, a 5\% de probabilidade (PIMENTEL GOMES, 2000).

\section{RESULTADOS E DISCUSSÃO}

$\mathrm{O}$ efeito do manejo do solo foi analisado quanto à estabilidade de agregados e expresso pelo diâmetro médio ponderado dos agregados (DMP), pelo índice de estabilidade dos agregados (IEA) e pela distribuição dos agregados estáveis em água, em classes de diâmetro médio.

\section{Diâmetro médio ponderado dos agregados (DMP)}

Os resultados do diâmetro médio ponderado dos agregados, em função dos diferentes sistemas de manejo e das quatro camadas de solo, são apresentados na Tabela 2.

Comparando-se os sistemas de manejo para cada camada de solo, verifica-se que não foram observadas diferenças significativas para o DMP entre os tratamentos. Entretanto, os resultados obtidos indicam tendência de maiores valores para a MA e menores para o PC, para todas as camadas.

Para o PC, observou-se que, na camada de 0,2-0,3 m, o DMP foi 1,74 vez maior que o da camada de 0,3-0,4 m, resultado que pode ser atribuído à ocorrência de compactação subsuperficial, causada pelos implementos agrícolas, durante os 22 anos de manejo do solo com o PC, comportamento semelhante ao observado por SILVA \& MIELNICZUK (1997b). 
TABELA 2. Diâmetro médio ponderado e índice de estabilidade de agregados para os três sistemas de manejo e as quatro camadas de solo

\begin{tabular}{|c|c|c|c|c|c|}
\hline \multirow{2}{*}{$\begin{array}{l}\text { Sistema de } \\
\text { Manejo }\end{array}$} & \multicolumn{4}{|c|}{ Camada (m) } & \multirow{2}{*}{ Média } \\
\hline & $0,0-0,1$ & $0,1-0,2$ & $0,2-0,3$ & $0,3-0,4$ & \\
\hline \multicolumn{6}{|c|}{ Diâmetro Médio Ponderado (mm) } \\
\hline MA & $4,51 \mathrm{aA}$ & $4,37 \mathrm{Aa}$ & $4,01 \mathrm{aA}$ & $3,31 \mathrm{aA}$ & $4,05 \mathrm{a}$ \\
\hline $\mathrm{PC}$ & $3,33 \mathrm{aAB}$ & 3,17 Aab & $4,01 \mathrm{aA}$ & $2,31 \mathrm{aB}$ & $3,21 \mathrm{~b}$ \\
\hline $\mathrm{PC} / \mathrm{SD}$ & $4,15 \mathrm{aA}$ & $3,78 \mathrm{Aa}$ & $3,26 \mathrm{aA}$ & $3,26 \mathrm{aA}$ & $3,61 \mathrm{ab}$ \\
\hline Média & $4,00 \mathrm{~A}$ & $3,77 \mathrm{AB}$ & $3,76 \mathrm{AB}$ & $2,96 \mathrm{~B}$ & \\
\hline C.V. $(\%)$ & & & & & \\
\hline dms & & & & & \\
\hline \multicolumn{6}{|c|}{ Índice de Estabilidade de Agregados (\%) } \\
\hline MA & $91 \mathrm{aA}$ & $89 \mathrm{Aa}$ & $88 \mathrm{aA}$ & $85 \mathrm{aA}$ & $88 \mathrm{a}$ \\
\hline $\mathrm{PC}$ & $78 \mathrm{bA}$ & $79 \mathrm{aA}$ & $85 \mathrm{aA}$ & $76 \mathrm{aA}$ & $79 \mathrm{~b}$ \\
\hline $\mathrm{PC} / \mathrm{SD}$ & $86 \mathrm{abA}$ & $85 \mathrm{aA}$ & $82 \mathrm{aA}$ & $84 \mathrm{aA}$ & $84 \mathrm{ab}$ \\
\hline Média & $85 \mathrm{~A}$ & $85 \mathrm{~A}$ & $85 \mathrm{~A}$ & $82 \mathrm{~A}$ & \\
\hline C.V. $(\%)$ & \multicolumn{4}{|c|}{6,76} & \\
\hline $\mathrm{dms}$ & \multicolumn{4}{|c|}{5,79} & \\
\hline
\end{tabular}

Médias seguidas de mesma letra, minúscula nas colunas e maiúscula nas linhas, não diferem para os sistemas de manejo, pelo teste de Tukey, a 5\% de probabilidade.

A comparação das médias das camadas mostrou diferença significativa para o DMP entre a MA e o PC, enquanto o tratamento PC/SD não mostrou diferença com a MA nem com o PC. Como não há diferença significativa do PC/SD com os demais, percebe-se uma melhora na estabilidade dos agregados em função da substituição do preparo convencional do solo pela semeadura direta.

Na Tabela 2, podem-se também observar os resultados de DMP para as quatro camadas de solo estudadas. A comparação entre as médias, pelo teste de Tukey ( $\mathrm{p} \leq 0,05)$, mostrou que ocorreram diferenças significativas entre as camadas de 0-0,1 e 0,3-0,4 m, resultado que está coerente com os teores de matéria orgânica, capacidade de troca catiônica, cálcio e magnésio do solo (Tabela 3), maiores para a camada de $0-0,1 \mathrm{~m}$, e que atuam como agentes cimentantes das partículas do solo, favorecendo maior estruturação.

Comparando-se os sistemas de manejo do solo, verifica-se que, tanto na camada superficial, entre $0-0,1 \mathrm{~m}$, como na média das camadas estudadas, o teor de cálcio encontrado para a MA foi maior do que o observado para o PC, respectivamente, 3,75 e 1,55 vezes. Esse elemento, conforme comenta FASSBENDER (1986), promove a floculação adequada das argilas além de contribuir para intensa atividade biológica que também favorece a agregação das partículas do solo. Para o magnésio, elemento que também promove a floculação das partículas do solo, também foram encontrados teores maiores na camada de 0-0,1 m e na média das camadas, respectivamente, 2,43 e 1,35 vezes. O potássio, que tem comportamento inverso, não diferiu significativamente entre a MA e o PC.

Embora os teores de potássio tenham sido maiores para o PC/SD, nas camadas de $0-0,1 ; 0,1-0,2$; 0,3-0,4 m e na média das camadas, pode-se inferir que esses teores não foram suficientes para inibir o efeito favorável da matéria orgânica, do cálcio e do magnésio na estabilidade dos agregados do solo. 
TABELA 3. Matéria orgânica, capacidade de troca catiônica, cálcio, magnésio e potássio, para os três sistemas de manejo e as quatro camadas de solo

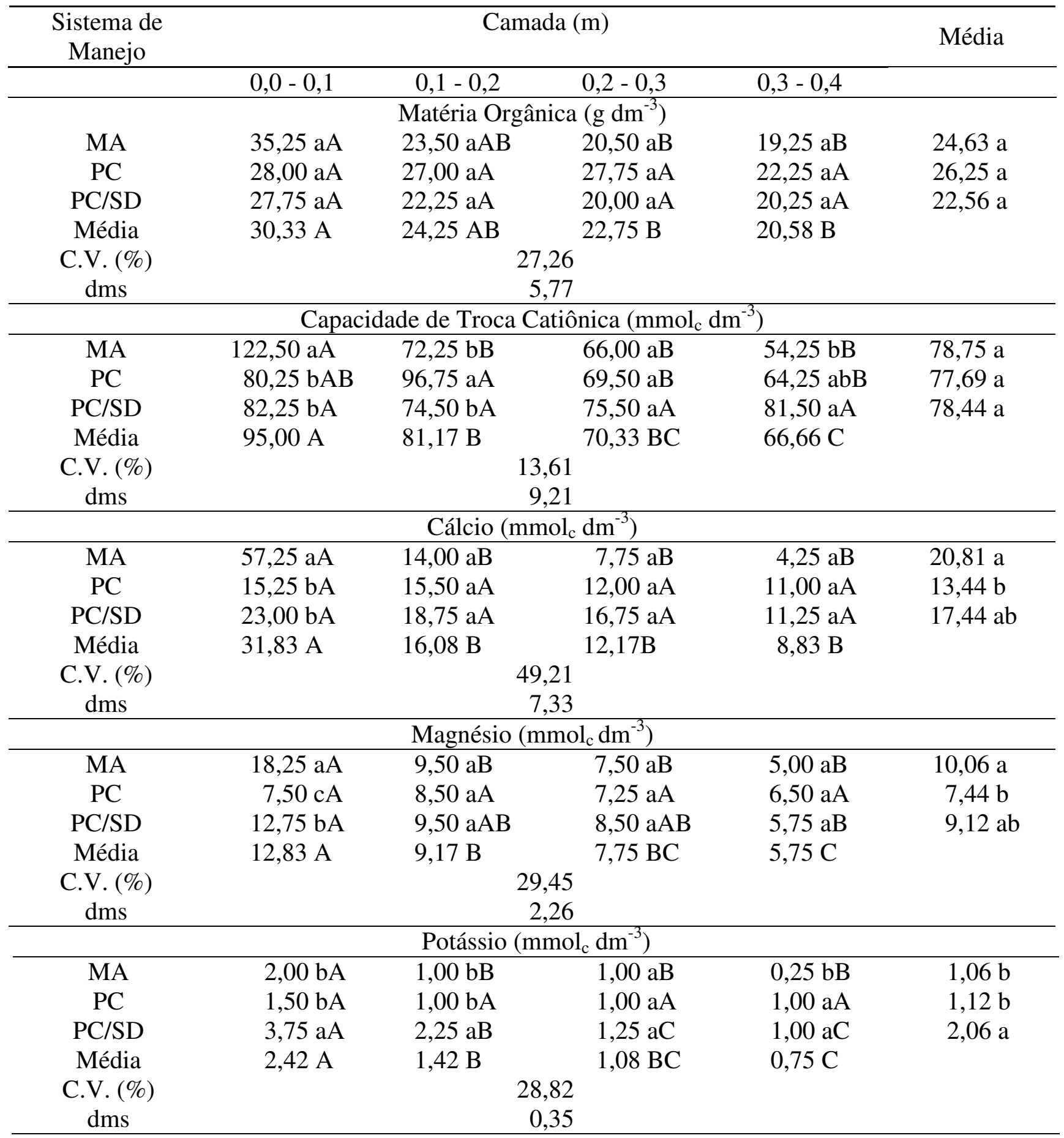

Médias seguidas de mesma letra, minúscula nas colunas e maiúscula nas linhas, não diferem para os sistemas de manejo, pelo teste de Tukey, a 5\% de probabilidade. 


\section{Índice de estabilidade de agregados (IEA)}

Para o IEA (Tabela 2), ocorreu diferença significativa entre os sistemas de manejo para a camada de 0,0-0,10 m. O solo sob MA apresentou IEA 1,17 vez maior que o solo submetido ao PC, ambos não diferindo significativamente do PC/SD. Na média dos tratamentos, o IEA do solo sob MA foi 1,11 vez maior que o do solo sob PC. Esses resultados são coerentes com os observados para os teores de cálcio e de magnésio (maiores) e de potássio (semelhantes) encontrados para o solo sob MA e estão de acordo com os observados por CASTRO FILHO et al. (1998); CARPENEDO \& MIELNICZUK (1990) e SILVA \& MIELNICZUK (1997b).

Para o IEA, também não foi observada diferença significativa entre o PC/SD e o PC, muito provavelmente porque a área sob PC/SD foi utilizada, inicialmente, por 10 anos em sistema de PC. Entretanto, os valores de IEA encontrados para o sistema PC/SD, para cada camada estudada, mostram uma tendência, evidenciando que a semeadura direta está agindo como um sistema de recuperação das características físicas desse solo, o que concorda com REINERT et al. (1984), VIEIRA \& MUZILLI (1984), CAMPOS et al. (1995) e MORAES et al. (2002).

\section{Distribuição dos agregados estáveis em água em classes de diâmetro médio}

As percentagens de agregados estáveis em água, para as classes estudadas, considerando desde os agregados maiores, entre 7,93 e 2,00 mm, até os menores que 0,10 mm, encontram-se na Figura 1.

Os valores médios de percentagem de agregados estáveis em água mostraram diferença significativa para a classe 7,93 a 2,00 mm, entre a MA e o PC, com valores de 91 e $65 \%$, respectivamente, na camada de $0-0,1 \mathrm{~m}$.

Para as demais camadas, os três sistemas de manejo não evidenciaram diferenças para cada classe de agregados. Para todas as camadas estudadas, a maior percentagem de agregados sempre foi observada para a classe 7,93-2,00 mm. Comparando-se as classes de agregados do solo sob MA e PC/SD com o PC, nas camadas de 0-0,1; 0,1-0,2 e 0,3-0,4 m, verifica-se que, para o solo sob PC, os agregados maiores que 2,00 $\mathrm{mm}$ foram fracionados pelo cultivo, para agregados com diâmetros menores, enquanto a melhor estrutura da MA e do PC/SD pode ser comprovada por meio da menor percentagem de agregados nas classes de menor diâmetro e maior nas de maior diâmetro, para todas as camadas. Esses resultados concordam com os obtidos por CARPENEDO \& MIELNICZUK (1990), BEUTLER et al. (2001) e CAMPOS et al. (1995).

Para a camada de 0,2-0,3 m, observa-se para o PC comportamento inverso ao que ocorreu para as demais camadas, ou seja, o PC apresentou maior percentagem de agregados para a classe 7,93$2,00 \mathrm{~mm}$ e menor percentagem nas classes intermediárias, comportamento que pode ser atribuído à compactação subsuperficial causada pelos implementos agrícolas durante os 22 anos de utilização do sistema. Resultados semelhantes também foram obtidos por SILVA \& MIELNICZUK (1977b). 

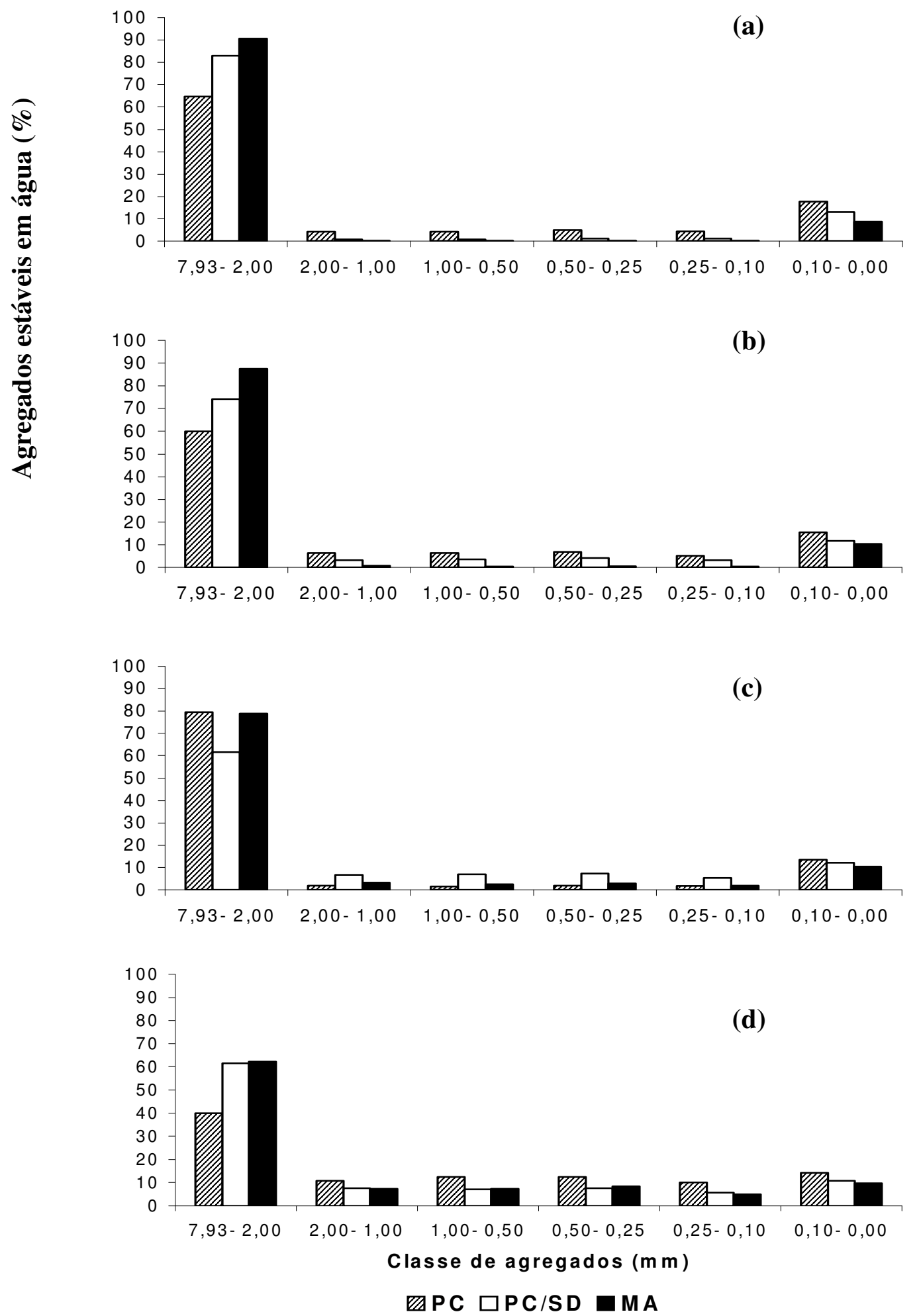

FIGURA 1. Distribuição dos agregados estáveis em água, nas camadas de 0,0-0,1 m (a); 0,1-0,2 m (b); 0,2-0,3 m (c), e 0,3-0,4 m (d), para os três sistemas de manejo de solo. 


\section{CONCLUSÕES}

O diâmetro médio ponderado e o índice de estabilidade dos agregados foram menores para o preparo convencional do solo em relação à mata.

A percentagem de agregados com diâmetro entre 7,93 e $2,00 \mathrm{~mm}$ foi menor para o preparo convencional do solo em relação à mata, na camada de $0-0,10 \mathrm{~m}$.

Os três sistemas de manejo apresentaram maior percentagem de agregados com diâmetro entre 7,93 e $2,00 \mathrm{~mm}$.

A substituição do preparo convencional pela semeadura direta favoreceu a estabilidade dos agregados do solo.

O diâmetro médio ponderado, o índice de estabilidade de agregados e a percentagem de agregados por classe de diâmetro médio evidenciaram diferenças entre os sistemas de manejo.

\section{REFERÊNCIAS}

BEUTLER, A.N.; SILVA, M.L.N.; CURI, N.; FERREIRA, M.M.; PEREIRA FILHO, I.A.; CRUZ, J.C. Agregação de Latossolo Vermelho distrófico típico relacionada com o manejo na região dos cerrados no Estado de Minas Gerais. Revista Brasileira de Ciência do Solo, Viçosa, v.25, n.1, p.12936, 2001.

CAMPOS, B.C.; REINERT, D.J.; NICOLODI, R.; RUEDELL, J.; PETRERE, C. Estabilidade estrutural de um Latossolo Vermelho-Escuro distrófico após sete anos de rotação de culturas e sistemas de manejo de solo. Revista Brasileira de Ciência do Solo, Campinas, v.19, n.1, p.121-6, 1995. CARPENEDO, V.; MIELNICZUK, J. Estado de agregação e qualidade de agregados de Latossolos Roxos, submetidos a diferentes sistemas de manejo. Revista Brasileira de Ciência do Solo, Campinas, v.14, n.1, p.99-105, 1990.

CARVALHO, W.A.; ESPÍNOLA, C.R.; PACCOLA, A.A. Levantamento de solos da Fazenda Lageado - Estação Experimental "Presidente Médici". Botucatu: Faculdade de Ciências Agronômicas, 1983. 95 p. (Boletim Técnico,1).

CASTRO FILHO, C.; MUZILLI, O.; PODANOSCHI, A.L. Estabilidade dos agregados e sua relação com o teor de carbono orgânico num Latossolo Roxo distrófico, em função de sistema de plantio, rotações de culturas e métodos de preparo das amostras. Revista Brasileira de Ciência do Solo, Viçosa, v.22, n.3, p.527-38, 1998.

EMPRESA BRASILEIRA DE PESQUISA AGROPECUÁRIA. Manual de métodos de análise de solo. 2.ed. Rio de Janeiro: Centro Nacional de Pesquisa de Solos, 1997. 212 p.

EMPRESA BRASILEIRA DE PESQUISA AGROPECUÁRIA. Centro Nacional de Pesquisa de Solos. Sistema brasileiro de classificação de solos. Rio de Janeiro, 1999. 412 p.

FASSBENDER, W.H. Quimica de suelos. San José, Costa Rica: IICA, 1986. 398 p.

KIEHL, E.J. Manual de edafologia. São Paulo: Agronômica Ceres, 1979. 264 p.

MORAES, M.H.; GOMAR, E.P.; BENEZ, S.H.; BARILLI, J. Effects of long-term management systems on soil quality. In: INTERNATIONAL SOIL CONSERVATION ORGANIZATION CONFERENCE, 12., 2002, Beijing. Proceedings ... Beijing: Tsinghua University Press, 2002. v.2, p.187-92.

PIMENTEL GOMES, F. Curso de estatística experimental. 14.ed. Piracicaba: (s.n.), 2000. 477 p. 
RAIJ, B. van.; QUAGGIO, J.A. Métodos de análise do solo para fins de fertilidade. Campinas: Instituto Agronômico, 1983. 31 p. (Boletim Técnico, 81)

REINERT, D.J.; MUTTI, L.S.M.; ZAGO, A.; AZOLIN, M.A.D.; HOFFMANN, C.L. Efeito de diferentes métodos de preparo do solo sobre a estabilidade de agregados em Solo Podzólico VermelhoAmarelo. Revista do Centro de Ciências Rurais, Santa Maria, v.14, n.1, p.19-25, 1984.

SILVA, I.F. da; MIELNICZUK, J. Ação do sistema radicular de plantas na formação e estabilidade de agregação do solo. Revista Brasileira de Ciência do Solo, Campinas, v.21, n.1, p.113-17, 1997a.

SILVA, I.F. da; MIELNICZUK, J. Avaliação do estado de agregação do solo afetado pelo uso agrícola. Revista Brasileira de Ciência do Solo, Campinas, v.21, n.2, p.313-19, 1997b.

VIEIRA, M.J.; MUZILLI, O. Características físicas de um Latossolo Vermelho-Escuro sob diferentes sistemas de manejo. Pesquisa Agropecuária Brasileira, Brasília, v.19, n.7, p.873-82, 1984. 